Brazilian Journal

of Chemical

ISSN 0104-6632

Printed in Brazil

Engineering

www.scielo.br/bjce

Vol. 35, No. 02, pp. 769 - 784, April - June, 2018

dx.doi.org/10.1590/0104-6632.20180352s20160522

(cc) BY

\title{
OPERATIONAL DESIGN AND IMPROVEMENT OF CONVENTIONAL BATCH DISTILLATION AND MIDDLE-VESSEL BATCH DISTILLATION
}

\author{
Xin $\mathrm{Li}^{1}$, Tingran Zhao ${ }^{1}$, Yong Wang ${ }^{1}$, Yinglong Wang ${ }^{1}$ and \\ Zhaoyou $\mathrm{Zhu}^{1 *}$ \\ ${ }^{1}$ College of Chemical Engineering, Qingdao University of Science and Technology, \\ Qingdao, 266042, China. Phone: +86-0532-84022751, Fax: +86-0532-84022751
}

(Submitted: September 2, 2016; Revised: March 11, 2017; Accepted: April 10, 2017)

\begin{abstract}
Conventional batch distillation and middle-vessel batch distillation were studied for the separation of the ternary system of cyclohexane/n-heptane/toluene, which has low relative volatilities. The modified variable and constant reflux operations were applied in the conventional batch distillation. Two control structures were used: one of which was referred to as the composition control structure with a modified level-set point, and the other was referred to as the flowrate-limiting control structure. Thus, the middle-vessel batch distillation was able to simultaneously separate the components of the ternary mixture. Comparing the two control structures showed that the flowrate-limiting control structure was better than the composition control structure with a modified level-set point in terms of their applicability. Disturbances were introduced to assess the controllability of the flowrate-limiting control structure. The dynamic responses demonstrated that the control structure performed well. The results showed that the modified conventional batch distillation and middle-vessel batch distillation increased the purity of the separated components compared to previous studies.
\end{abstract}

Keywords: Batch distillation, Middle vessel, Control structure, Ternary system.

\section{INTRODUCTION}

Batch distillation is widely used in the pharmaceutical industry to purify and recover highvalue liquid components. It has better operational flexibility and reduces equipment costs compared to continuous distillation (Jimenez et al., 2002; Narvaes-Garcia et al., 2015). Over many years of improvement, batch distillation processes have been developed that can be used in special distillation processes, such as pressure-swing distillation (Modla, 2011; Repke et al., 2007), extractive distillation
(Fang et al., 2010; Navarrete-Contreras et al., 2014; Pacheco-Basulto et al., 2012), and reactive distillation (Khazraee and Jahanmiri, 2010; Modla, 2011), which are based on different column configurations, including conventional and unconventional column configurations.

Conventional batch distillation can be operated in several modes, and the performance of the operation modes is different. Many researchers (Bai et al., 2007; García et al., 2014; Lopes and Song, 2010) have studied operation optimization and made contributions to the process. However, the column

*E-mail: huagongyl@163.com 
cannot be used to separate components simultaneously when the mixtures contain more than two components.

Unconventional column configurations, including inverted batch distillation columns, middle-vessel batch distillation (MVBD) columns, and multivessel batch distillation columns, have all been studied in order to solve more complex situations, such as multicomponent separation (Mujtaba, 2004).

MVBD columns have gained considerable attention because of their great flexibility (Gruetzmann et al., 2006; Leipold et al., 2009; Warter et al., 2004). The middle vessel between the rectifying and stripping sections can act as a feed tank and product vessel. In the case of a separation of a ternary mixture, for instance, the lightest/heaviest components are collected at the top/bottom, while the intermediate component is purified in the vessel simultaneously. Additionally, the vessel can be used as an additional reboiler or condenser so that one more degree of freedom is added, thus making the process more flexible. Quintero-Marmol and Luyben (1990) have explored the operation modes of multicomponent batch distillation columns. One of them, known as fed-batch distillation, involves a setup with two middle vessels, which results in a higher capacity factor than in the regular mode. Davidyan et al. (1994) theoretically analyzed the dynamic behavior of MVBD and revealed the influence of the parameters. This paper has widely prompted the development of MVBD. Meski and Morari (1995) solved the optimal control problem of MVBD in the case of a binary separation and found that the minimum reflux model was the best suited control policy. Barolo et al. (1996) carried out experimental runs in a pilot plant-scale continuous distillation column that had been modified to implement batch operations. Then, Barolo et al. (1998) developed a detailed model to investigate the effect of the operating and design parameters. Warter et al. (2002) compared the experimental and simulation results of separating a ternary zeotropic system in a cyclic operation with a constant holdup, and they explained the limits of the geometrical and operational parameters. Diwekar (2011) comprehensively analyzed the behavior of the process in a shortcut model, rigorous model and semi-rigorous model. Rao and Barik (2012) studied the effects of reboiler heat duty, reflux flowrate and number of plates on the product composition and dealt with the control of the distillate composition and condenser holdup. In addition, the studies of MVBD columns have been extended to several special distillation processes. Cheong and Barton (1999a, 1999b, 1999c) used the concept of warped time analysis to develop a mathematical model and studied the qualitative dynamics of MVBD for the separation of azeotropic mixtures in a case where the separation boundaries were linear and nonlinear. Warter and Stichlmair (2000) described three MVBD processes for the separation of a binary azeotropic mixture using an entrainer and found that, when the liquid from the upper section was sent to the lower section directly, the process performed best. Low and Sørensen (2002) investigated the optimal operations of MVBD columns used in extractive distillation based on a profit function. Control strategies are essential for the process to achieve high-purity products. Phimister and Seider $(2000 \mathrm{a}, 2000 \mathrm{~b})$ studied two distillatebottom (DB) control configurations and overcame the associated deficiencies, such as low product purity. Gruetzmann and Fieg (2008) analyzed and discussed the initiation of an MVBD column and used a temperature control structure to investigate the process. Fanaei et al. (2012) compared the control structures of conventional middle-vessel batch distillation and modified middle-vessel batch distillation, and they found that level controllers could obtain high purity products when the feed composition was kept constant. Luyben (2015) studied the control structures of MVBD for separating a ternary system, and the results showed that a composition control structure and temperature control structure could perform well for controlling the product purity and liquid holdup. Zhu et al. (2016) compared the composition control structure and two temperature control structures and found that the temperature control structures performed better.

In this paper, we studied the conventional batch distillation process and MVBD process for the separation of a ternary system of cyclohexane $/ \mathrm{n}$ heptane/toluene, which is difficult to separate because of their low relative volatilities. More efficient operations in the conventional batch distillation were adopted, and new control structures in the MVBD were explored to stabilize the product purity and liquid holdup. Both distillation processes could effectively separate the ternary mixture into high-purity products.

\section{MODIFIED OPERATIONS OF CONVENTIONAL BATCH DISTILLATION}

Conventional batch distillation for the separation of the mixture of cyclohexane/n-heptane/toluene was simulated by Aspen Batch Distillation with the SRK model and was operated under two modes: variable reflux and constant reflux. The number of stages was set at 41 , which was large enough to separate the ternary system through conventional batch distillation (Figure 1a) and the MVBD (Figure 1b). 


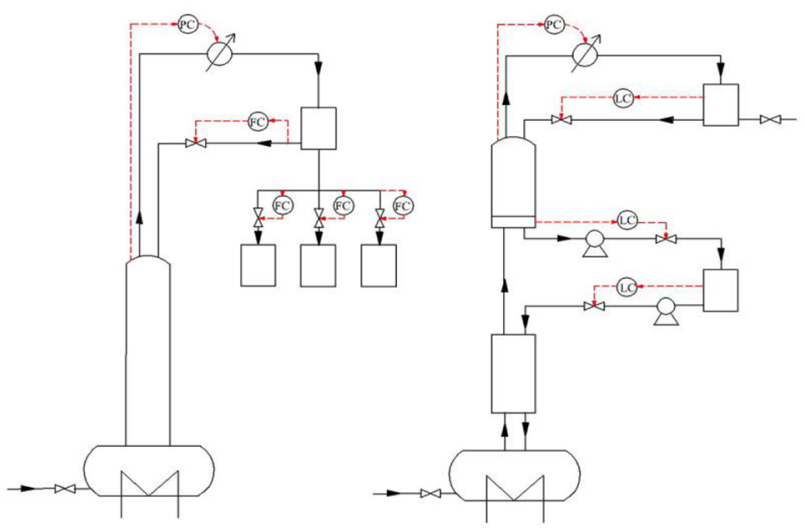

Figure 1. The flowsheets of: (a) conventional batch distillation; and (b) middle-vessel batch distillation.

\section{Modified variable reflux operation}

A modified variable reflux operation was used to maintain the component purity in the corresponding product vessel at a desired value by changing the reflux ratio. The liquid holdup of the feed in the bottom was set at $1000 \mathrm{kmol}$ with a composition of $40.7 \mathrm{~mol} \%$ cyclohexane, $39.4 \mathrm{~mol} \% \mathrm{n}$-heptane, and $19.9 \mathrm{~mol} \%$ toluene (Jain et al., 2012). Three product receivers were connected with the distillate stream to collect the main-cuts and off-cuts. Receiver 1 was used to collect high-purity cyclohexane at step 1, and receiver 3 was employed to gather high-purity n-heptane at step 3 . On the other hand, receiver 2 was used to collect a mixture of cyclohexane and n-heptane that did not meet the purity demands of the products at step 2 . The column was operated at atmospheric pressure, and the modified operation steps are shown in Table 1.

The medium heating temperature of the setup was based on the temperature of 5-atm saturated steam (absolute pressure), which has a sufficient difference in temperature from the boiling points of the mixture. In the modified steps, the distillate mole flowrate in each step had an impact on the product purities and liquid holdups. Figure 2 shows the effects of distillate flowrate on the key factors of each step.

It should be noted that the distillate flowrate in step 3 slightly influenced the mole fraction of $n$-heptane in the third receiver when the rate was less than $4 \mathrm{kmol} / \mathrm{h}$.
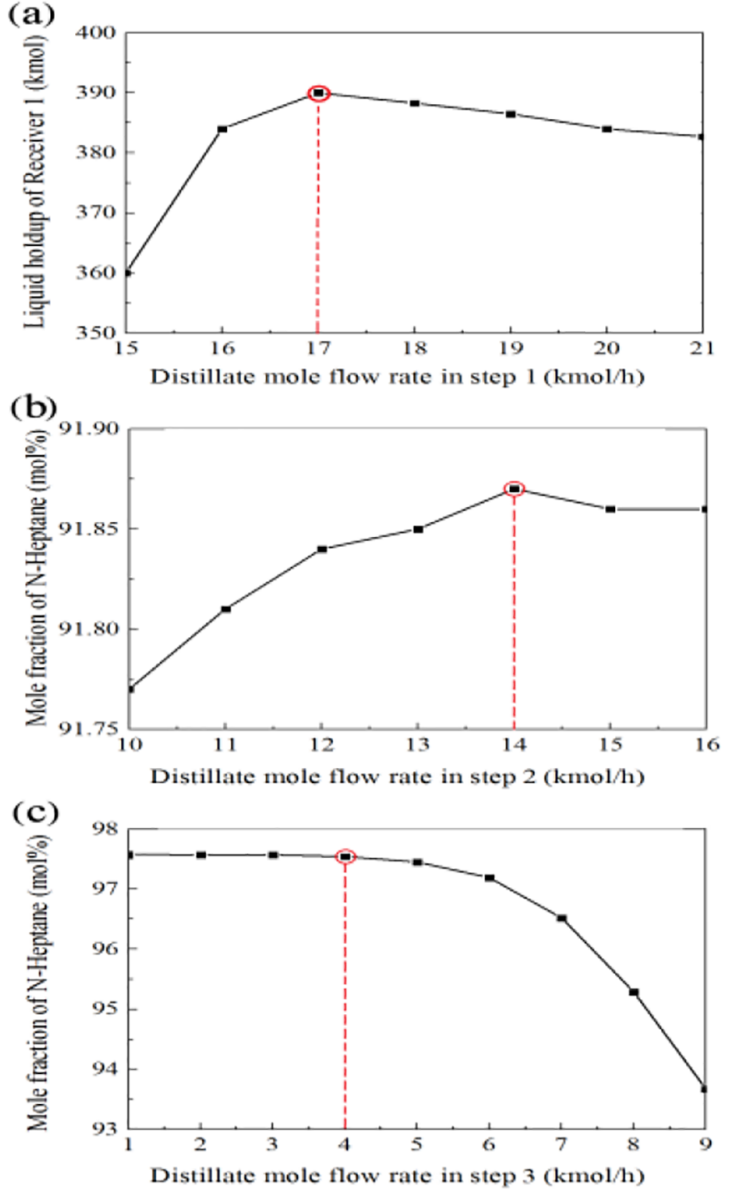

Figure 2. Effect of distillate mole flow: (a) on Receiver 1 liquid holdup in step 1; (b) on n-heptane mole fraction in step 2; and (c) on n-heptane mole fraction in step 3 .

Increasing the distillate flowrate could decrease the batch time; therefore, $4 \mathrm{kmol} / \mathrm{h}$ was selected as one of the operating parameters. The mole fraction $(\mathrm{X})$ and liquid holdup (M) in the three product vessels and the reflux ratio are shown in Figure 3 and Table 2.

The modified variable reflux operation could achieve higher purity of the three products, especially for cyclohexane and n-heptane, compared to the results of a previous study (Jain et al., 2012), which reported product purities of $89.3 \mathrm{~mol} \%$ cyclohexane, $86.3 \mathrm{~mol} \% \mathrm{n}$-heptane, and $99.1 \mathrm{~mol} \%$ toluene.

Table 1. Modified steps of the variable reflux operation.

\begin{tabular}{lccc}
\hline Set Variables & Step 1 & Step 2 & Step 3 \\
\hline $\mathbf{F}_{\mathbf{d}}(\mathbf{k m o l} / \mathbf{h})$ & 17 & 14 & 4 \\
$\mathbf{T}_{\mathrm{hm}}\left({ }^{\circ} \mathbf{C}\right)$ & 150 & 150 & 150 \\
Sequence of receivers & No. 1 & No. 2 & No. 3 \\
End conditions & $\mathrm{X}_{\text {receiver } 1, \mathrm{cyc}}=99 \mathrm{~mol} \%$ & $\mathrm{X}_{\mathrm{pot}, \mathrm{cyc}}=1 \mathrm{~mol} \%$ & $\mathrm{X}_{\mathrm{pot}, \mathrm{tol}}=99 \mathrm{~mol} \%$ \\
\hline
\end{tabular}



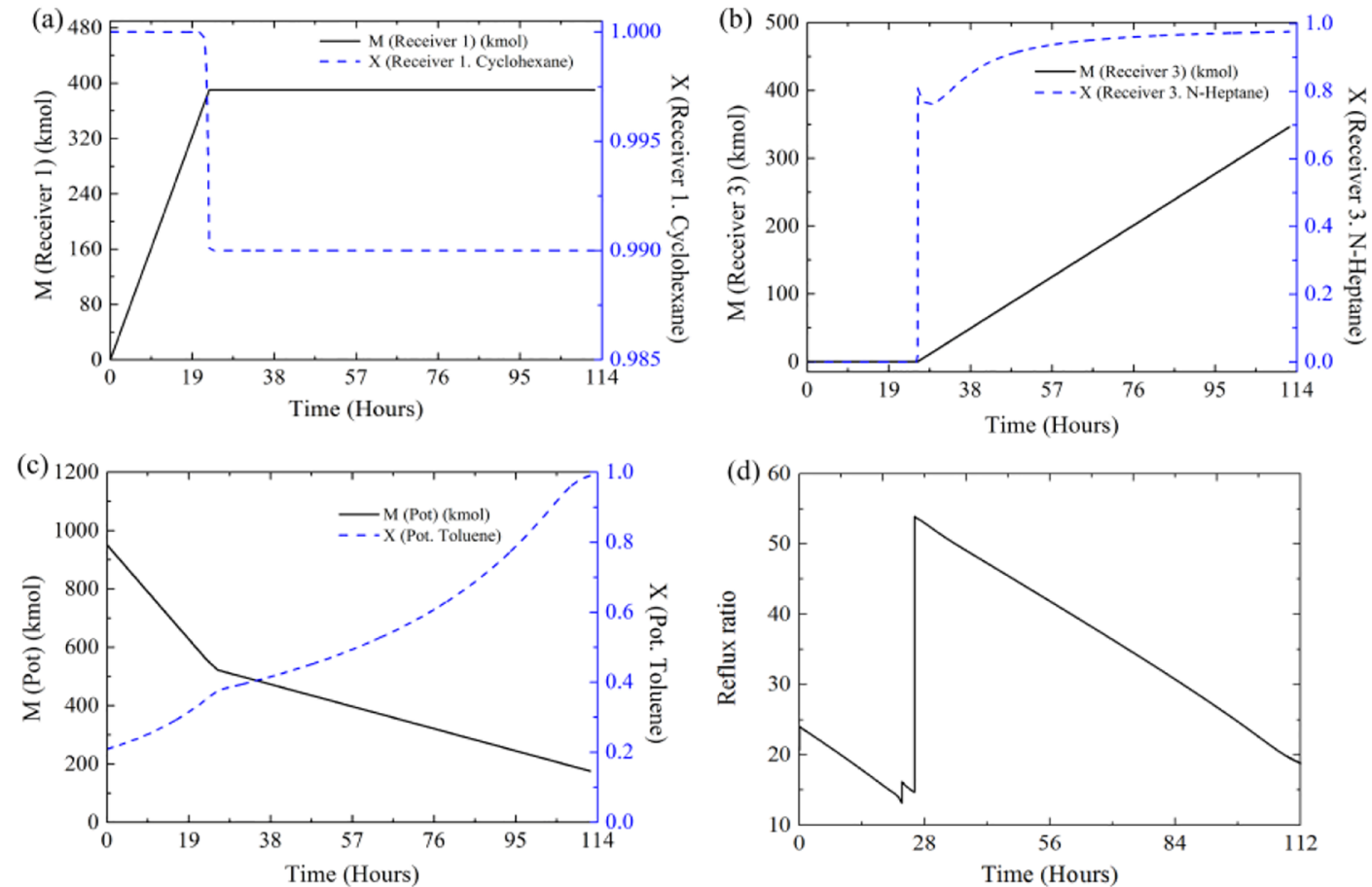

Figure 3. Variation trends of: (a), (b), (c) product purity and liquid holdup; and (d) reflux ratio.

Table 2. Results of the modified variable reflux operation.

\begin{tabular}{lcccc}
\hline Parameters & Receiver 1 & Receiver 2 & Receiver 3 & Pot \\
\hline $\mathbf{X}_{\text {cyclo }}(\mathbf{m o l} \%)$ & 99.0 & 33.5 & 2.3 & trace \\
$\mathbf{X}_{\text {n-hep }}(\mathbf{m o l} \%)$ & 1.0 & 66.4 & 97.5 & 1.0 \\
$\mathbf{X}_{\text {tol }}(\mathbf{m o l} \%)$ & trace & 0.1 & 0.2 & 99.0 \\
$\mathbf{M}(\mathbf{k m o l})$ & 390.1 & 38.9 & 346.2 & 175.7 \\
\hline
\end{tabular}

\section{Modified constant reflux operation}

The modified constant reflux operation allowed the achievement of products with the desired purity by fixing the reflux ratio. The initial settings in this operation were the same as the modified variable reflux operation, and three vessels were used to collect the products and byproducts. The reflux ratio was set to 15 because the mole fraction of $n$-heptane was already higher than $99.0 \mathrm{~mol} \%$ and remained almost constant with the increase of the reflux ratio (Figure 4).

The modified operation steps are shown as Table 3.

The end condition of the second step was that the overall holdup of the receiver reached 140.0 kmol because the setting had positive impact on the n-heptane quantity and purity $(>99.0 \mathrm{~mol} \%)$. The results of the constant reflux operation are shown in Table 4 and Figure 5.

The two operation modes of conventional batch distillation separated the ternary system of cyclohexane/n-heptane/toluene efficiently, and the

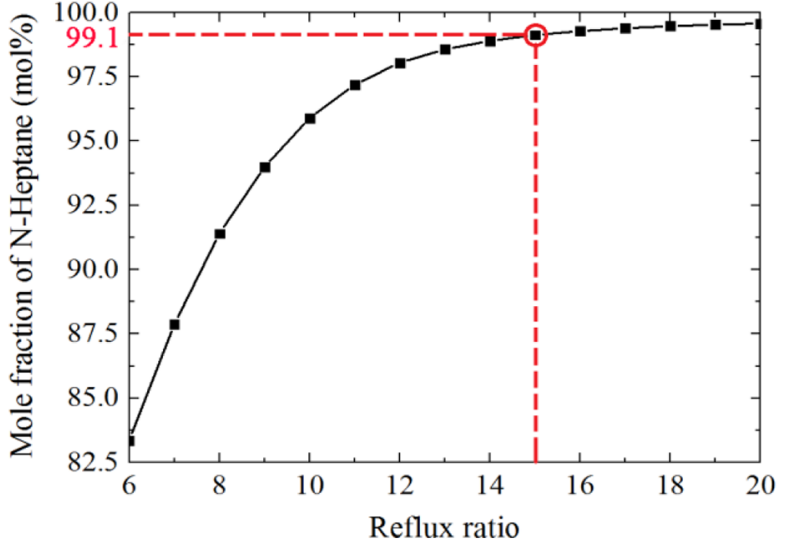

Figure 4. Mole fraction of n-heptane under different reflux ratios.

purities of cyclohexane and n-heptane were improved. However, the conventional batch process could not separate the components simultaneously. As an important unconventional batch distillation process, MVBD could overcome the bottleneck as a result of effective control structures. 
Table 3. Modified steps of the constant reflux operation.

\begin{tabular}{|c|c|c|c|}
\hline Set Variables & Step1 & Step2 & Step3 \\
\hline Reflux ratio & 15 & 15 & 15 \\
\hline $\mathbf{T}_{\mathrm{hm}}\left({ }^{\circ} \mathrm{C}\right)$ & 150 & 150 & 150 \\
\hline Sequence of receivers & No.1 & No. 2 & No.3 \\
\hline End conditions & $X_{\text {receiver1, cyc }}=99 \mathrm{~mol} \%$ & $\mathrm{M}_{\text {receiver2 }}=140 \mathrm{kmol}$ & $X_{\text {pot }, \text { tol }}=99 \mathrm{~mol}^{\circ}$ \\
\hline
\end{tabular}

Table 4. Results of the modified constant reflux operation.

\begin{tabular}{|c|c|c|c|c|}
\hline Parameters & Receiver 1 & Receiver 2 & Receiver 3 & Pot \\
\hline$X_{\text {cyclo }}(\mathrm{mol} \%)$ & 99.0 & 14.4 & 0.2 & trace \\
\hline$X_{n-\text { hep }}(\mathbf{m o l} \%)$ & 1.0 & 85.4 & 99.1 & 1.0 \\
\hline $\mathrm{X}_{\mathrm{tol}}(\mathrm{mol} \%)$ & trace & 0.2 & 0.7 & 99.0 \\
\hline M (kmol) & 390.2 & 140 & 253.7 & 167.1 \\
\hline
\end{tabular}
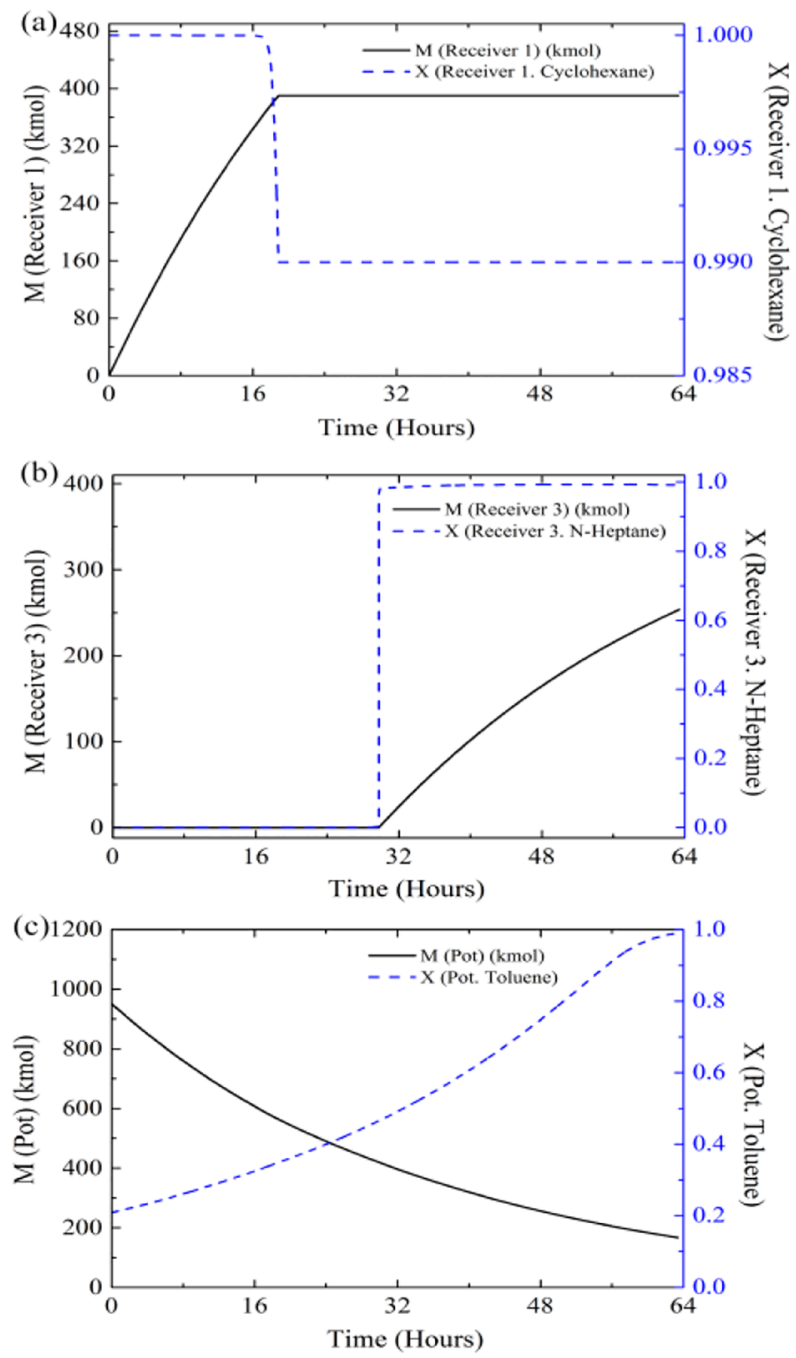

Figure 5. Variation trends of product purity and liquid holdup.

\section{DESIGN AND CONTROL OF MIDDLE- VESSEL BATCH DISTILLATION}

MVBD, as a typical model of unconventional batch distillation, was studied using Aspen Plus and Aspen
Plus Dynamics in this section. The SRK physical properties were selected, and the basic setup procedure was similar to that proposed by Luyben (2015), although the control structures were different.

\section{Process setup in steady-state Aspen Plus}

The MVBD column was simulated by two Radfrac models, with one being used as the rectifying section and the other as the stripping section. In addition, a Flash 2 model was used to simulate the middle vessel. Several valves and pumps were added to change the pressure of the streams. More details about the simulation are shown in Table 5.

The flowsheet of the MVBD is shown in Figure 6, and the feed stream was set at $1000 \mathrm{kmol} / \mathrm{h}$ with a composition of $40.7 \mathrm{~mol} \%$ cyclohexane, $39.4 \mathrm{~mol} \%$ n-heptane, and $19.9 \mathrm{~mol} \%$ toluene. The column and middle vessel were operated at atmospheric pressure. The size of each vessel needed to be large enough to accommodate the components based on the feed volume. The process could not be defined completely as a batch distillation process because there were several feed streams. Some adjustments were carried out to implement the batch process in a dynamic simulation.

The results of the steady-state processes show that there was almost $100 \mathrm{~mol} \%$ cyclohexane in the reflux drum and $99 \mathrm{~mol} \%$ cyclohexane in the middle vessel. A mixture of $41.0 \mathrm{~mol} \%$ cyclohexane, 39.0 mol\% $\mathrm{n}$-heptane, and $20.0 \mathrm{~mol} \%$ toluene remained in the sump (Table 6). These results mean that MVBD is unlike continuous distillation because the separation of the mixture in MVBD required an efficient control structure to implement. 
Table 5. Simulation details in steady-state Aspen Plus.
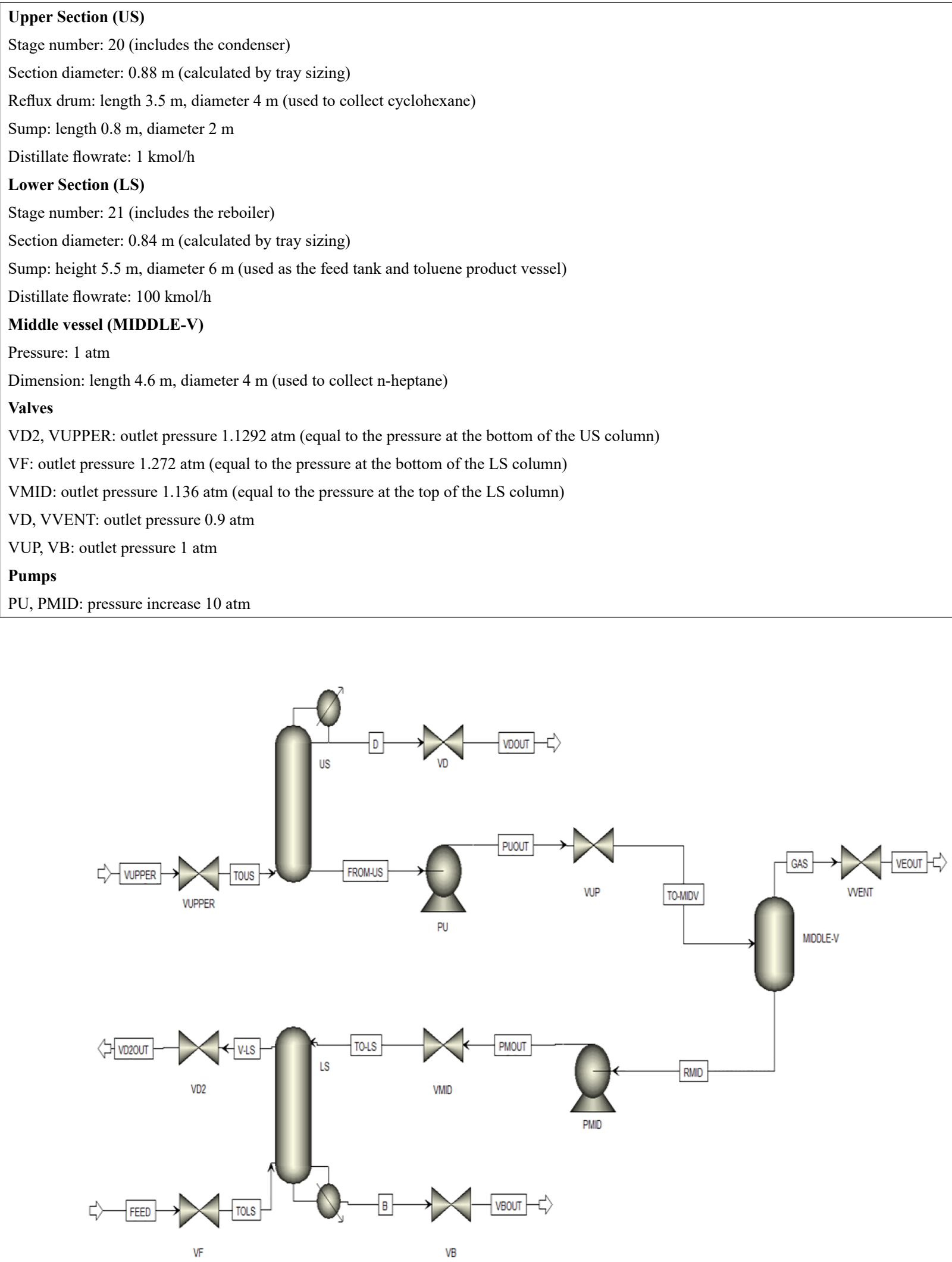

Figure 6. The flowsheet of the middle-vessel batch distillation. 
Table 6. Stream results of the steady-state simulation.

\begin{tabular}{|c|c|c|c|c|c|c|c|c|}
\hline Parameters & $\mathrm{D}$ & RMID & $\mathrm{B}$ & GAS & TO-LS & FEED & VUPPER & FROM-US \\
\hline$F_{\text {total }}(\mathrm{kmol} / \mathrm{h})$ & 1.00 & 98.99 & 998.99 & 0.001 & 98.99 & 1000.00 & 100.00 & 99.00 \\
\hline $\mathrm{F}_{\text {cyclo }}(\mathrm{kmol} / \mathrm{h})$ & 1.00 & 97.99 & 405.70 & 0.001 & 97.99 & 407.00 & 99.00 & 98.00 \\
\hline $\mathrm{F}_{\mathrm{n}-\mathrm{hep}}(\mathrm{kmol} / \mathrm{h})$ & Trace & 1.00 & 394.29 & Trace & 1.00 & 394.00 & 1.00 & 0.01 \\
\hline $\mathrm{F}_{\text {tol }}(\mathrm{kmol} / \mathrm{h})$ & - & - & 199.00 & - & - & 199.00 & - & - \\
\hline$X_{\text {cyclo }}$ & 1.00 & 0.99 & 0.40 & 0.99 & 0.99 & 0.41 & 0.99 & 0.99 \\
\hline $\mathbf{X}_{\text {n-hep }}$ & 8PPM & 0.01 & 0.40 & 0.01 & 0.01 & 0.39 & 0.01 & 0.01 \\
\hline $\mathbf{X}_{\text {tol }}$ & - & - & 0.20 & - & - & 0.20 & - & - \\
\hline
\end{tabular}

Level control structure with a temperature controller

In the dynamic mode, the valves VD, VVENT, VF, and VB were closed by setting their openings to zero. The streams VUPPER and VD2OUT, and the valve VUPPER were deleted when the stream TOUS was connected to the valve VD2. Therefore, the system became a closed system, and it could be defined as a batch distillation process.

The mixture was fed into the sump of the LS column, then the sump was heated. The operating pressure of the process was $1 \mathrm{~atm}$. With the temperature increase, almost all the light component (cyclohexane) and a certain amount of the intermediate component (n-heptane) were vaporized and moved up into the condenser at the top of the column. Part of the condensed mixture was refluxed to ensure the high purity of the light component in the reflux drum; thus, the reflux flowrate was important for the cyclohexane content. Then, the mixture was refluxed back to the column, and liquid holdup was established in the trays and in the middle vessel. The sump of the US column held the liquid to be pumped into the middle vessel. As the temperature of the sump in the LS column increased further, the composition of n-heptane in the middle vessel was profoundly influenced by the toluene that boiled up into the US column. As a result, the heat duty of the reboiler and the reflux flowrate to the LS column should be controlled strictly. When the process became steady, the components should be collected with high purity in the reflux drum, middle vessel and sump of LS column. The composition, level, and flowrate were correlated with each other, and the control structures needed to be set to achieve effective separation.

Level control structures (LCS) have been studied in batch distillation (Fanaei et al., 2012; Luyben, 2015) and continuous distillation processes, such as pressure swing distillation (Wei et al., 2013; Zhu et al., 2015), reactive distillation (Xu et al., 2014), and extractive distillation (Wang et al., 2015). In this paper, three level controllers named LCtop, LCbase, and LCmid, a temperature controller called TCLS and a pressure controller called PC were added to stabilize the separation system. The detailed control structure is as follows:

1. The heat duty of the condenser in the column was manipulated (reverse acting) to control the operating pressure of the column.

2. The flowrate at the top (direct acting) was manipulated to control the level of the reflux drum in the US column.

3. The flowrate at the bottom (direct acting) was manipulated to control the base level in the US column.

4. The flowrate (direct acting) was manipulated to control the level in the middle vessel.

5. The heat duty of the reboiler in the column (reverse acting) was manipulated to control the temperature of stage 1 so that the toluene content that boiled up into the US column could be hindered.

It should be noted that the action of the PC is set as reverse for the value of the condenser duty is negative in the Aspen Dynamics. The flowsheet of LCS with a temperature controller is shown in Figure 7. The results demonstrated that the purity of cyclohexane and toluene was larger than $99.5 \mathrm{~mol} \%$, while n-heptane was only $71.0 \mathrm{~mol} \%$. In terms of the liquid holdup in the three product vessels, there were only $20.5 \mathrm{kmol}$ in the reflux drum, $32.6 \mathrm{kmol}$ in the middle vessel, and $84.5 \mathrm{kmol}$ in the sump (Figure 8). Hence, it was important to explore a control structure to improve the product purity.

\section{Composition control structure}

Composition control structures (CCS) often perform better than LCS for improving product purity. A composition controller named CCtop, which was used to control the n-heptane content in the reflux drum by manipulating the reflux flowrate, and a high selector named HStop, which was a MultiHiLoSelect model, were set in the flowsheet (Figure 9). When 


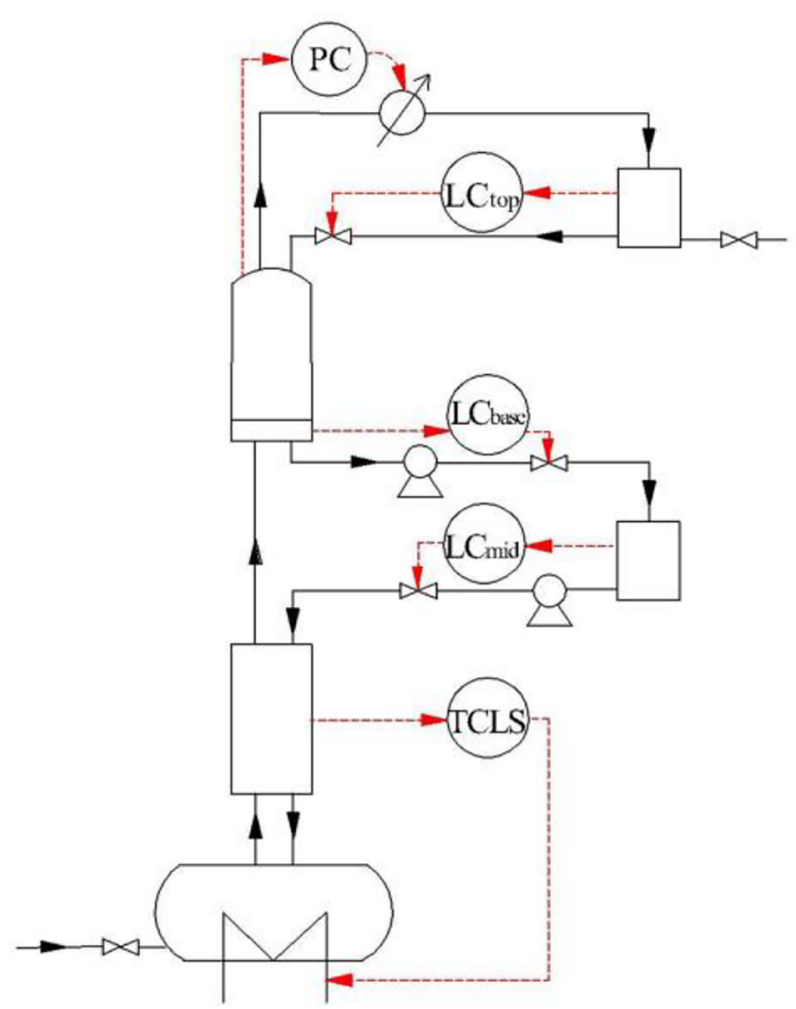

Figure 7. The flowsheet of the level control structure with a temperature controller. the mole fraction of $n$-heptane in the reflux drum was higher than the set point, the reflux flowrate would be increased by the direct action of CCtop. HStop was used to select the larger value between "Input_1" and "Input 2" as the output signal and then to control the reflux flowrate of the upper section column. "Input_1" is a fixed value $(8626 \mathrm{~kg} / \mathrm{h})$ that was almost equal to the initial value of the reflux flowrate, and the "Input_2" was the CCtop controller output signal. The parameters of controllers are significant for the performance, and there are differences between the tuning methods used in continuous distillation and batch distillation. Several tuning methods could be used in distillation processes, such as the Tyreus-Luyben method (Tyreus and Luyben, 1992), IMC method (Rivera et al., 1986), and SIMC method (Skogestad, 2003, 2006), and they each have their own advantages when used under different conditions. For continuous distillation, we applied the Tyreus-Luyben tuning rule to calculate the gain and integral time when the process became steady-state. However, for batch distillation, especially for MVBD, the process variables were changing; thus, the Tyreus-Luyben tuning rule could not be used at the beginning. To solve this problem, the gain and integral
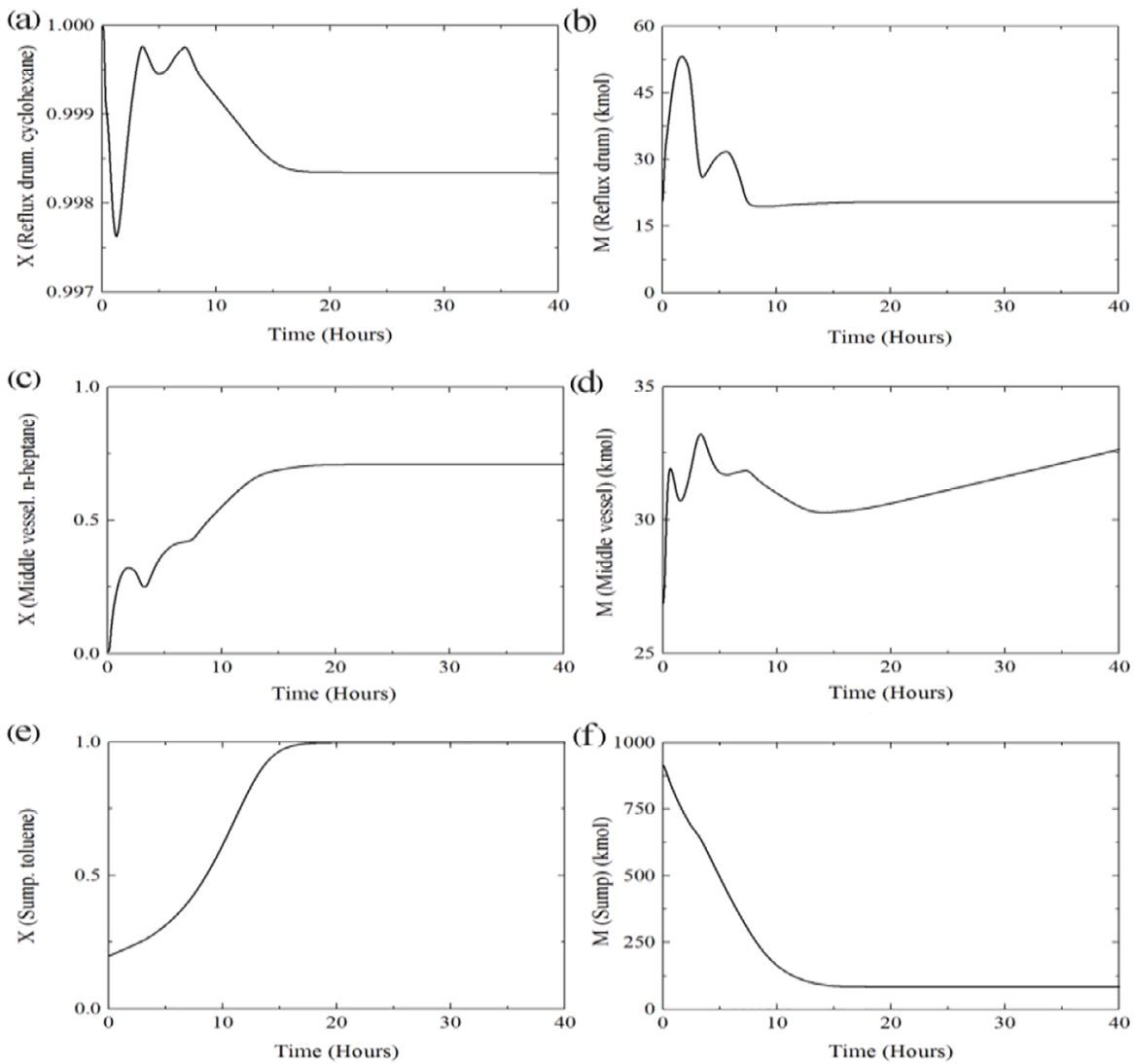

Figure 8. Results of the level control structure with a temperature controller. 
time of the controllers were set empirically until the purities of products were stable at a high level, then the Tyreus-Luyben tuning was initiated to calculate the more appropriate gain and integral time. The gain and integral time of the composition controller CCtop were set to 5 and 20 min empirically, while those of the temperature controller TCLS were set to 1 and $20 \mathrm{~min}$. When the product purities were high and constant, the Tyreus-Luyben tuning method was applied to calculate the more appropriate gains and integral times for the two controllers. Table 7 shows the parameters of each controller in the CCS.

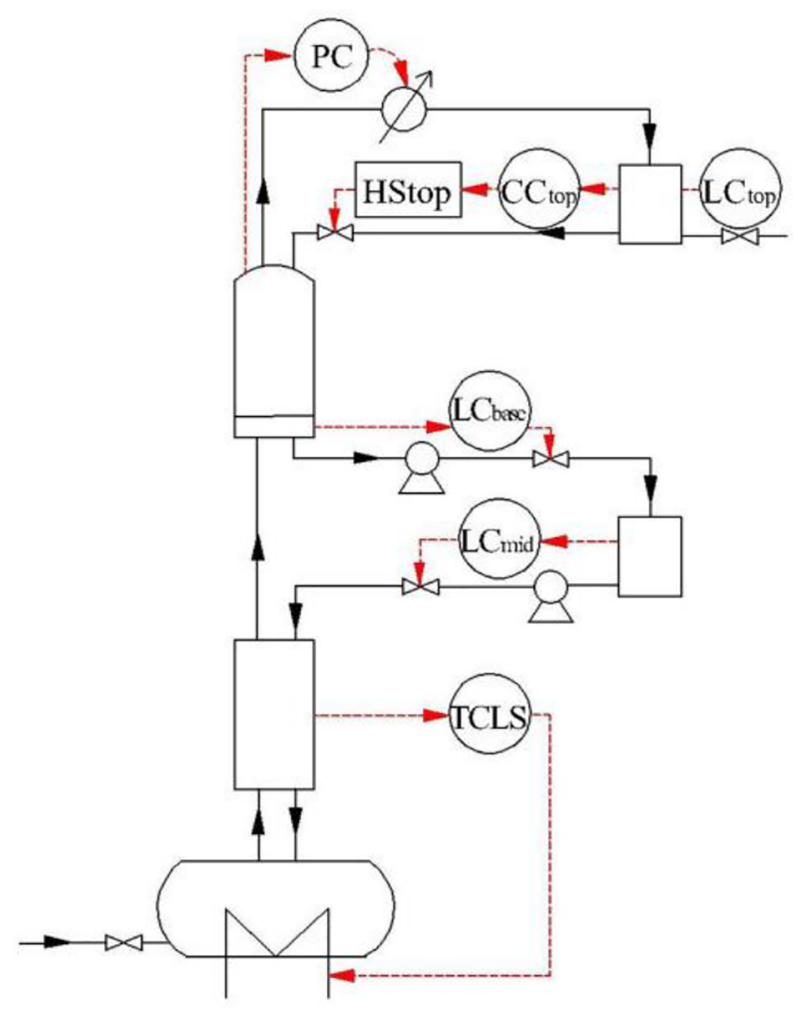

Figure 9. The flowsheet of the composition control structure.

Figure 10 shows that the cyclohexane purity decreased from $99.9 \mathrm{~mol} \%$ to $99.0 \mathrm{~mol} \%$ because a small amount of n-heptane entered into the reflux drum, while the toluene content continuously increased to $99.3 \mathrm{~mol} \%$ in the sump as the light and the intermediate components boiled up. In terms of the n-heptane content, it was difficult to end up at 99.0 mol\% due to the low relative volatility of $n$-heptane/ toluene, and a certain amount of toluene was easily delivered into the middle vessel with n-heptane. The final liquid holdup was $297.9 \mathrm{kmol}$ in the reflux drum and $117.2 \mathrm{kmol}$ in the sump. However, it was only $29.0 \mathrm{kmol}$ in the middle vessel because the flowrate of stream RMID was approximately equal to that of stream TO-MIDV (Figure 11a). To have a high liquid holdup in the product vessels, the flowrate of output streams needed to be smaller than that of input streams so that it was possible to assemble the amounts of the liquid products (Figure $11 \mathrm{~b}$ and 11c).

\section{Composition control structure with a modified level-set point}

In the composition control structure, the level of the middle vessel, which could reflect the liquid holdup, was manipulated by LCmid, and the set point of the controller was crucial to this level. Therefore, the level of the middle vessel could be controlled to increase the liquid holdup, i.e., to indirectly decrease the flowrate of the output stream RMID. However, it should be noted that the flowrate from the vessel represented the reflux flowrate to the LS column. The decrease of the reflux flowrate could cause more toluene to boil up into the US column, which would lower the purity of n-heptane in the middle vessel. The relationship between the level in the middle vessel, n-heptane concentration, and liquid holdup of the middle vessel were investigated to determine an optimized value of the set point in LCmid to ensure that the liquid holdup was as high as possible while keeping the n-heptane content at $92.0 \mathrm{~mol} \%$. Figure 12 shows the effects of the level in the middle vessel on the n-heptane mole fraction and liquid holdup. When the level was $1.5 \mathrm{~m}$, the composition of n-heptane was $92.0 \mathrm{~mol} \%$, and the liquid holdup was the highest. Therefore, the set point of level controller LCmid was set at 1.5. Table 8 gives the results of the composition control structure with and without the modified set point of LCmid. It was clear that the liquid holdup of the middle vessel was increased by $119.3 \mathrm{kmol}$, which meant that indirectly decreasing the flowrate of the output stream RMID by controlling the level of the middle vessel was feasible. However, Figure 11b shows that the flowrate of the output stream decreased immediately to zero at $1 \mathrm{~h}$ and then rose up. The high liquid holdup of the middle

Table 7. The tuning parameters of the controllers in the composition control structure.

\begin{tabular}{lccccc}
\hline Parameters & PC & CCtop & TCLS & LCbase & LCmid \\
\hline gain $\mathbf{K}_{\mathbf{c}}$ & 20 & 6.642 & 124.264 & 1 & 1 \\
integral time $\boldsymbol{\tau}_{\mathbf{I}}(\mathbf{m i n})$ & 12 & 50.16 & 2.64 & 20 & 20 \\
\hline
\end{tabular}



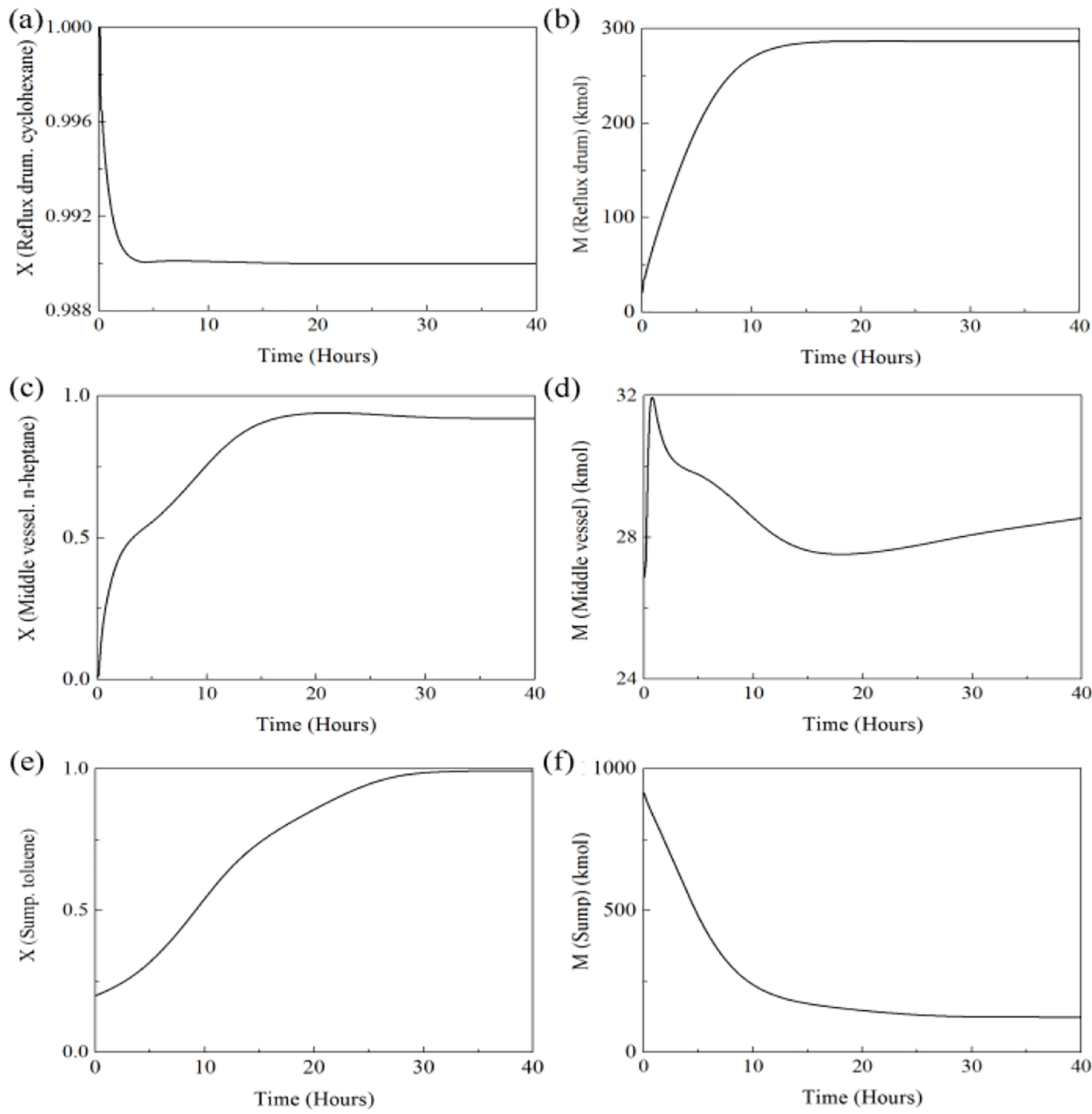

Figure 10. The results in terms of product purity and liquid holdup in each vessel.

vessel was formed during the first $3 \mathrm{~h}$, then it changed slightly in terms of quantity, while the composition changed gradually.

\section{Flowrate-limiting control structure}

The flowrates of the streams are usually controlled by flowrate controllers in the continuous and batch distillation processes. To decrease the flowrate of the output stream RMID, there is another way to directly implement control by adding a flowrate controller (Figure 13). When the flowrate increased, the opening of the valve would be smaller because of the reverseaction of the controller, then the flowrate was reduced, which increased the liquid holdup in the middle vessel. Compared to the CCS with a modified level-set point, the liquid holdup in the middle vessel could be controlled by the flowrate controller and the n-heptane mole fraction could still be as high as $92.0 \mathrm{~mol} \%$ based on the following analysis and results. Therefore, it was not necessary to specifically investigate the relationship between the level in the middle vessel and n-heptane concentration so that the flowrate-limiting control structure (FLCS) was more applicable. Figure 11c shows that the flowrate of stream TO-MIDV was larger than that of stream RMID in the first $18 \mathrm{~h}$, indicating that the high liquid holdup in the middle vessel was formed during this period. Then, the difference between the flowrate of the two streams decreased and they eventually became almost equal to each other. The fluctuation that occurred at $20 \mathrm{~h}$ in the TO-MIDV flowrate curve was caused by the oscillation in the cyclohexane content of the reflux drum. The increase in the cyclohexane content reduced reflux flowrate to the upper section column by the function of CCtop. 

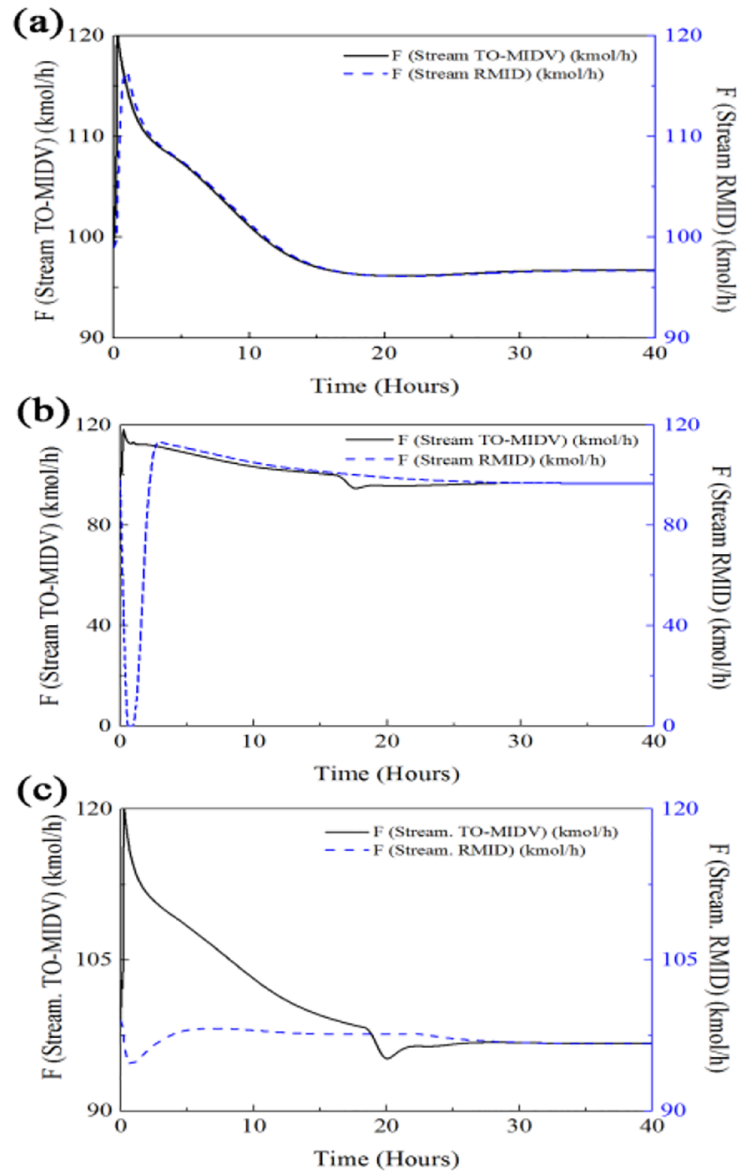

Figure 11. Flowrate comparison of the inlet and the outlet streams of the middle vessel in the composition control structure.

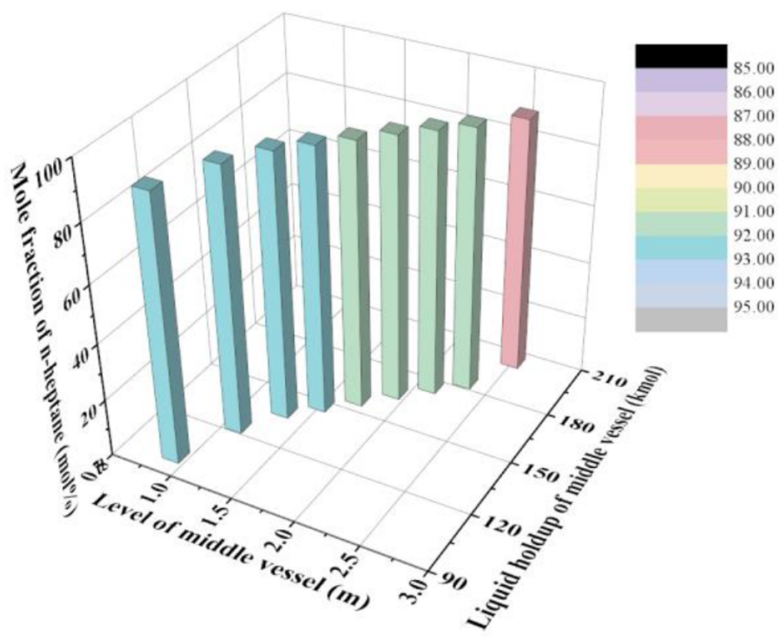

Figure 12. The effects of the level in the middle vessel on n-heptane content and liquid holdup.
Then, the liquid level of the sump in the column dropped, and the opening of valve VUP decreased. Consequently, the flowrate of stream TO-MIDV was reduced by the direct-acting level controller LCbase. In addition, the flowrate-limiting control structure was different from the proposed control structure in our published paper (Zhu et al., 2016). The relative volatility of methyl formate/methanol/water is much larger than that of cyclohexane/n-heptane/toluene, which makes the difficulty of separating the latter higher than the difficulty of separating the former. The function of the controllers and the principle of control structures in the two papers are also different.

In the FLCS (Figure 13), the cyclohexane in the reflux drum and the toluene in the sump of the LS column obtained purities of $99.0 \mathrm{~mol} \%$, whereas the n-heptane content in the middle vessel was up to 92.0 mol\%, which was better than in the previous study ( ${ }^{\text {Jain }}$ et al. ${ }^{2012}$ ). The liquid holdup was $297.5 \mathrm{kmol}$ in the reflux drum, $150.1 \mathrm{kmol}$ in the middle vessel, and $113.9 \mathrm{kmol}$ in the sump. All the results are shown in Figure 14, and they demonstrate that the control structure performed well.

The dynamic control performances of the FLCS were tested by adding initial liquid amount disturbances and initial composition disturbances. The liquid amount disturbances were changed by $\pm 10 \%$. The initial composition disturbances were introduced by changing the initial intermediate component (n-heptane) concentration from $39.4 \mathrm{~mol} \%$ to $47.3 \mathrm{~mol} \%$ and $31.5 \mathrm{~mol} \%( \pm 20 \%)$. The other two components were split by the original proportion. The composition of cyclohexane was changed from $40.7 \mathrm{~mol} \%$ to $35.4 \mathrm{~mol} \%$ and $46.0 \mathrm{~mol} \%$, while the composition of toluene was changed from $19.9 \mathrm{~mol} \%$ to $17.3 \mathrm{~mol} \%$ and $22.5 \mathrm{~mol} \%$. Figure $15 \mathrm{a}$ shows the dynamic response of the $+10 \%$ liquid amount disturbance. The product purities and liquid holdups were controlled stably. In the reflux drum, the liquid holdup was $329.54 \mathrm{kmol}$, with a composition of 99.0 mol\% cyclohexane. The liquid holdup of the middle vessel is $167.79 \mathrm{kmol}$, with a composition of $92 \mathrm{~mol} \%$ n-heptane. In the sump of the LS column, the liquid holdup is $128.45 \mathrm{kmol}$, with $99.3 \mathrm{~mol} \%$ toluene. The other disturbances are shown in Figures 15b, 16a, and $16 \mathrm{~b}$. All the purities of cyclohexane and toluene met the $99.0 \mathrm{~mol} \%$ mark, and the n-heptane concentration was stable at $92.0 \mathrm{~mol} \%$. The controllability of the FLCS performed well based on the dynamic responses. 
Table 8. The results of the composition control structure with (1) and without (2) the modified level-set point.

\begin{tabular}{lcc}
\hline Parameters & CCS $^{1}$ & CCS $^{2}$ \\
\hline $\mathbf{X}_{\text {cyclo }}(\mathbf{m o l} \%)$ & 99.0 & 99.0 \\
$\mathbf{X}_{\text {n-hep }}(\mathbf{m o l} \%)$ & 92.0 & 92.0 \\
$\mathbf{X}_{\text {tol }}(\mathbf{m o l} \%)$ & 99.3 & 99.3 \\
$\mathbf{M}_{\text {reflux drum }}(\mathbf{k m o l})$ & 301.5 & 286.8 \\
$\mathbf{M}_{\text {mid-v }}(\mathbf{k m o l})$ & 147.8 & 28.5 \\
$\mathbf{M}_{\text {pot }}(\mathbf{k m o l})$ & 106.9 & 123.6 \\
\hline
\end{tabular}

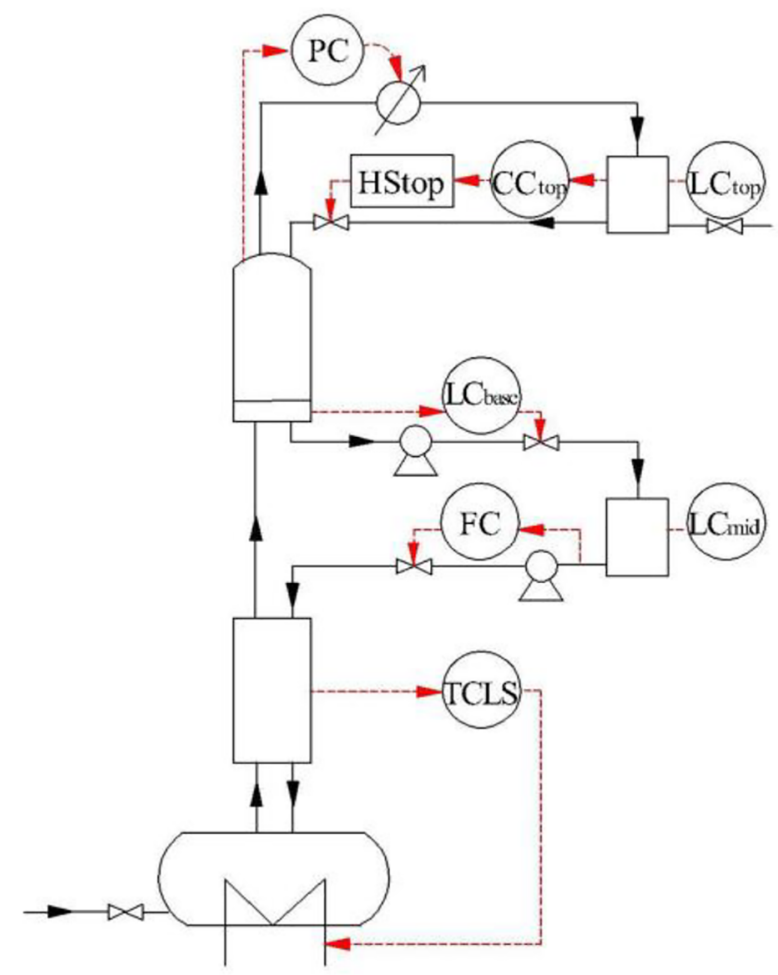

Figure 13. The flowsheet of the flowrate-limiting control structure.

\section{CONCLUSIONS}

Conventional batch distillation and MVBD were studied to separate a mixture of cyclohexane/nheptane/toluene. The modified operations applied in the conventional batch distillation resulted in obtaining a higher purity of product. However, due to the features of the conventional process, the ternary mixture could not be separated simultaneously, which would keep the batch time long.

MVBD, a more flexible batch process, allowed the collection of the intermediate component in the middle vessel and made it possible to separate the ternary system at the same time. The CCS with a modified level-set point and the FLCS were explored with the goal of achieving high product purity and liquid holdup. Based on the simulation results, the product purities achieved through using the two control structures were the same, although the liquid holdup was slightly different. The liquid holdup of the middle vessel and the sump in the FLCS were higher than in the CCS with a modified level-set point. In addition, when using the FLCS to control the process, it was not necessary to specifically investigate the relationship between the liquid level in the middle vessel and n-heptane concentration, which made FLCS more applicable than CCS with a modified level-set point. Therefore, when we use the MVBD to separate ternary mixtures with low relative volatility, similar to the ternary system in this paper, FLCS can be preferentially chosen. To assess the controllability of the control structure, liquid amount disturbances and initial composition disturbances were introduced. Based on the dynamic responses, all the purities and liquid holdups of the products were stable at a high level, which showed good performance of the control structure. The FLCS could potentially be carried out in practice, and it offers guidelines for practical processes. Both the level controllers and the flowrate controllers are already used in industry. For the composition controller, although it is difficult to achieve accurate online detection, the purity of the light component in the control structure was kept sufficiently high during the whole process based on the simulation results. Therefore, some other methods, such as gas chromatography, could be used, and the time delay caused by determining the purity would not impact the benefits of the process.

\section{ACKNOWLEDGEMENTS}

Support from the projects of the National Natural Science Foundation of China (Project 21676152 and Project 21306093) are gratefully acknowledged. 

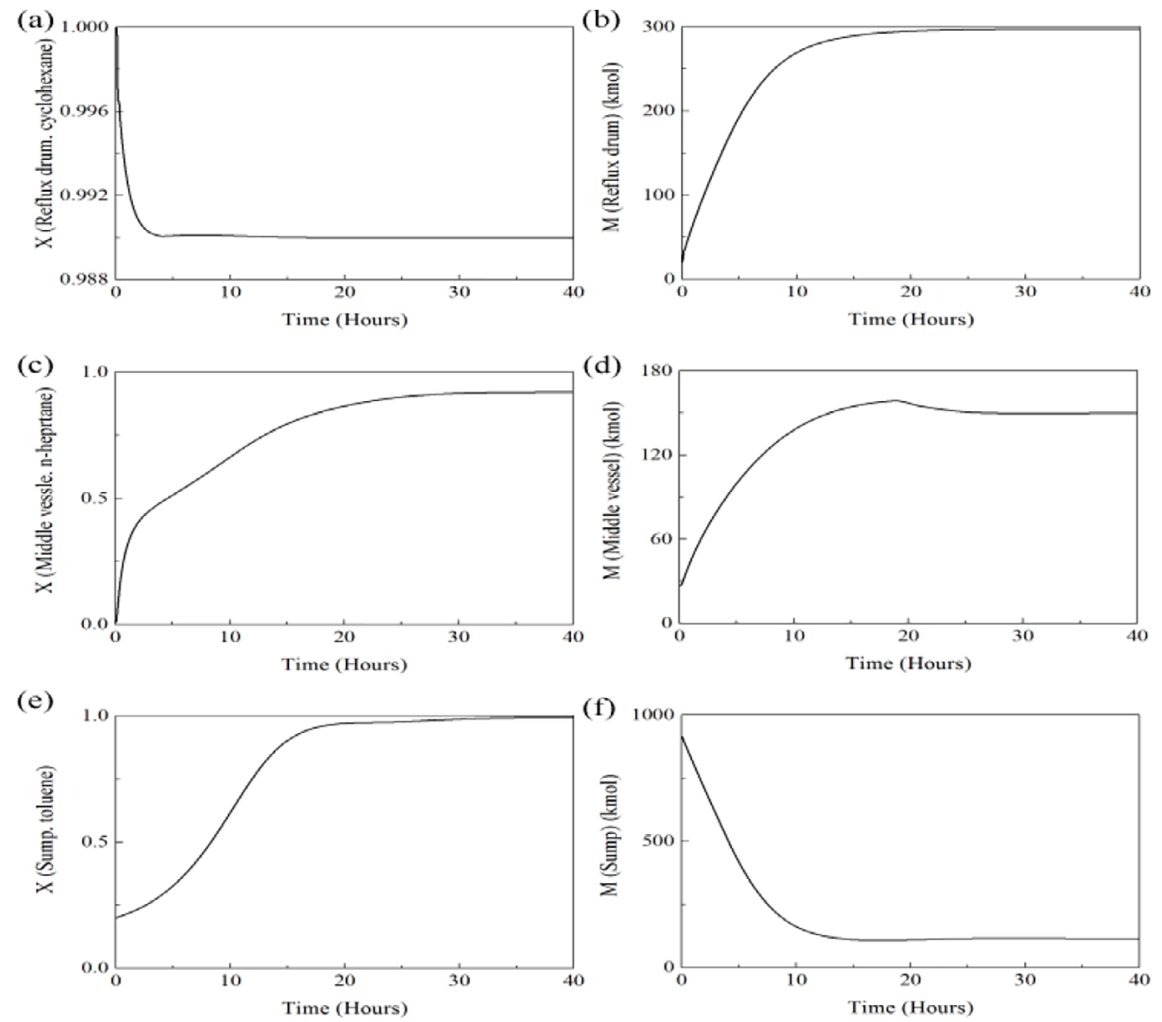

Figure 14. Results of the flowrate-limiting control structure.

(a)
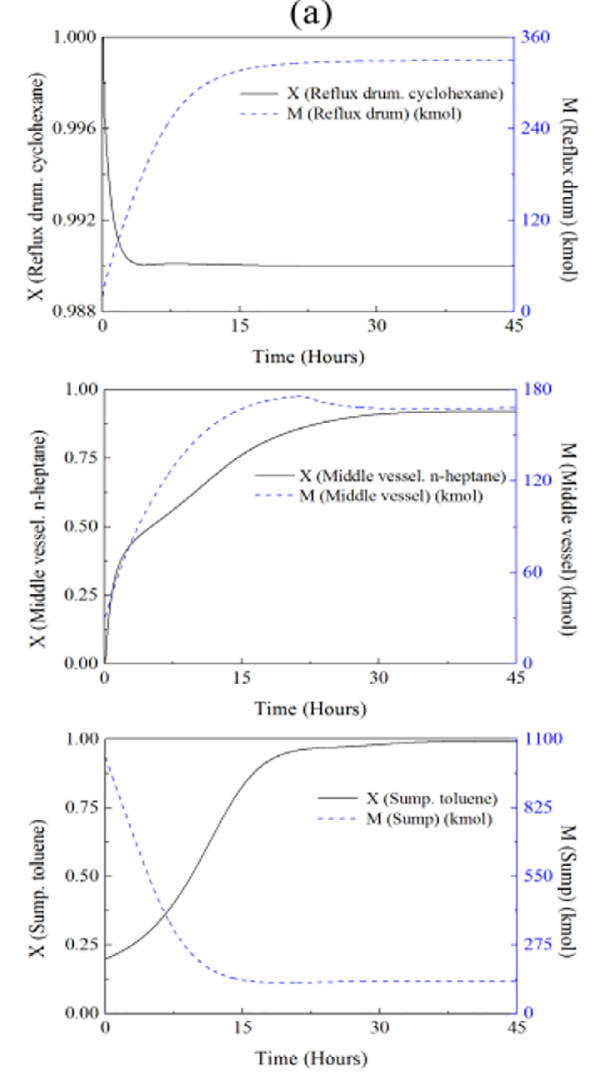

(b)
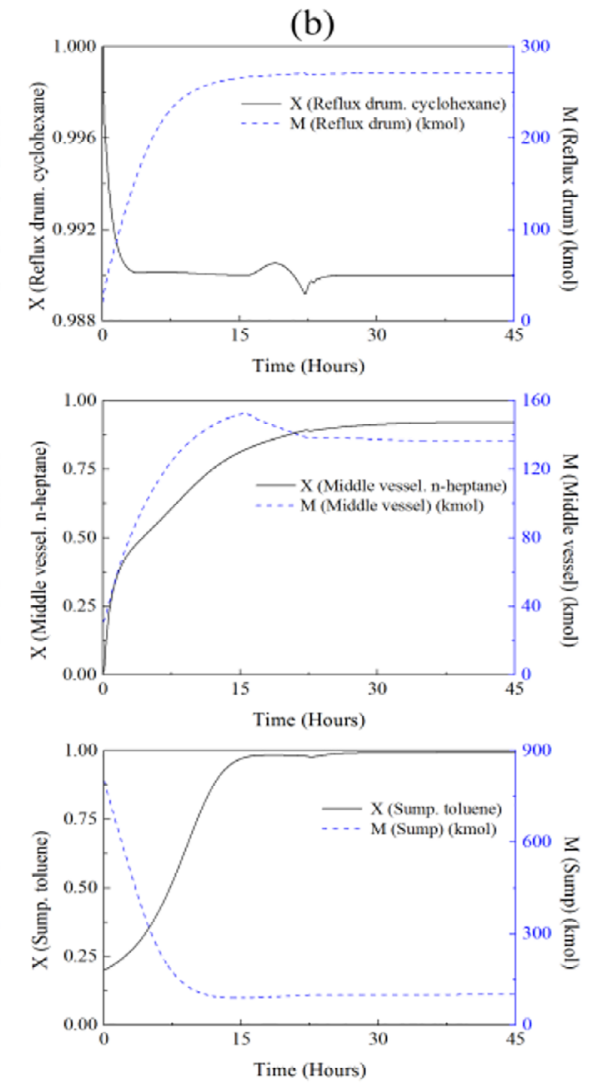

Figure 15. Dynamic responses of the liquid amount disturbances: (a) $+10 \%$; (b) $-10 \%$. 
(a)
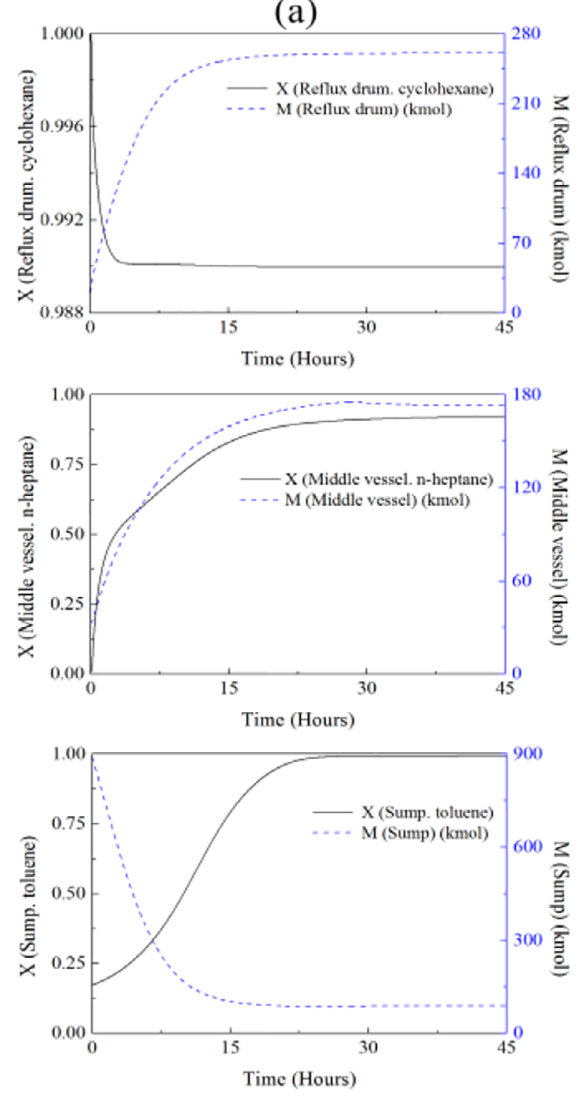

(b)
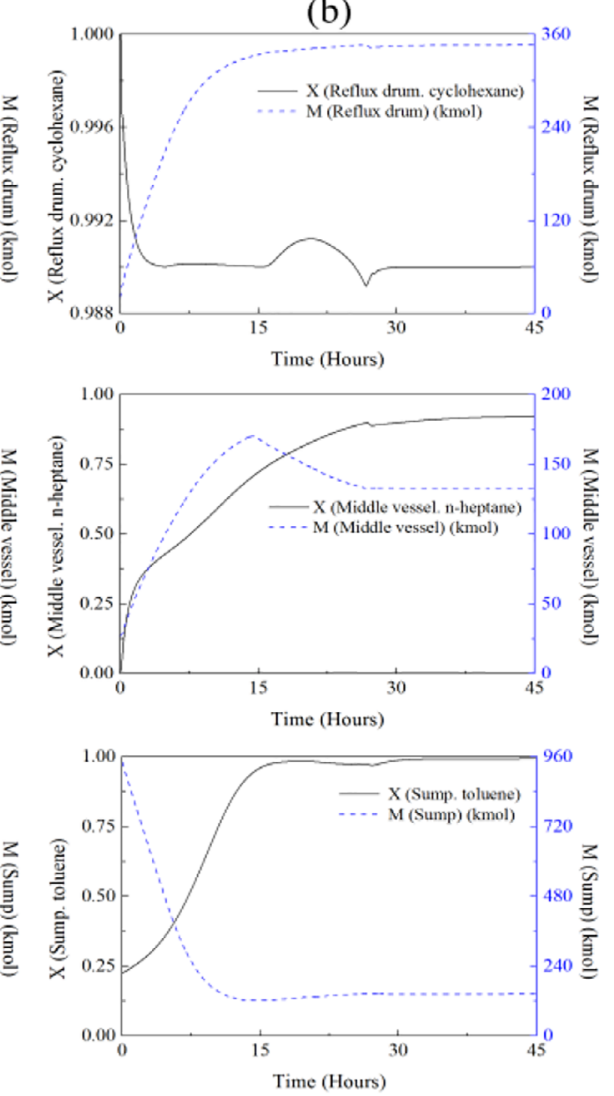

Figure 16. Dynamic responses of the initial composition disturbances: (a) $+20 \%$; (b) $-20 \%$.

\section{NOMENCLATURE}

CCS - Composition control structure

$\mathrm{F}$ - Mole flowrate $(\mathrm{kmol} / \mathrm{h})$

$\mathrm{F}_{\text {cyclo }}$ - Cyclohexane mole flowrate $(\mathrm{kmol} / \mathrm{h})$

$\mathrm{F}_{\mathrm{d}}$ - Distillate mole flowrate $(\mathrm{kmol} / \mathrm{h})$

$\mathrm{F}_{\text {n-hep }}-\mathrm{n}$-heptane mole flowrate $(\mathrm{kmol} / \mathrm{h})$

$\mathrm{F}_{\text {tol }}$ - Toluene mole flowrate $(\mathrm{kmol} / \mathrm{h})$

$\mathrm{F}_{\text {total }}$ - Total mole flowrate $(\mathrm{kmol} / \mathrm{h})$

FLCS - Flowrate-limiting control structure

LCS - Level control structure

LS - Lower section

M - Liquid holdup (kmol)

$\mathrm{M}_{\text {mid-v }}$ - Liquid holdup of the middle vessel (kmol)

$\mathrm{M}_{\text {pot }}^{\text {mid-v }}$ - Liquid holdup of the pot (kmol)

$\mathrm{M}_{\text {reflux drum }}^{\text {pot }}$ Liquid holdup of the reflux drum (kmol)

MVBD - Middle-vessel batch distillation

$\mathrm{T}$ - Temperature $\left({ }^{\circ} \mathrm{C}\right)$

$\mathrm{T}_{\mathrm{hm}}$ - Temperature of heat medium $\left({ }^{\circ} \mathrm{C}\right)$

TCS - Temperature control structure

US - Upper section

$\mathrm{X}$ - Mole fraction $(\mathrm{mol} \%)$

$\mathrm{X}_{\text {cyclo }}$ - Cyclohexane mole fraction $(\mathrm{mol} \%)$

$\mathrm{X}_{\mathrm{n} \text {-hep }}$ - n-Heptane mole fraction $(\mathrm{mol} \%)$

$\mathrm{X}_{\text {tol }}$ - Toluene mole fraction $(\mathrm{mol} \%)$

\section{REFERENCES}

Bai, P., Li, X., Sheng, M., Song, S., Zhao, G., Li, X., Study of dual temperature control method on cyclic total reflux batch distillation. Chemical Engineering and Processing: Process Intensification, 46 (8) 769772 (2007).

Barolo, M., Guarise, G.B., Rienzi, S.A., Trotta, A., Running Batch Distillation in a Column with a Middle Vessel. Industrial \& Engineering Chemistry Research, 35 4612-4618 (1996).

Barolo, M., Guarise, G.B., Rienzi, S.A., Trotta, A., Understanding the Dynamics of a Batch Distillation Column with a Middle Vessel. Computers \& Chemical Engineering, 22 37-44 (1998).

Cheong, W. and Barton, P.I., Azeotropic Distillation in a Middle Vessel Batch Column. 1. Model Formulation and Linear Separation Boundaries. Industrial \& Engineering Chemistry Research, 38, 1504-1530 (1999a).

Cheong, W. and Barton, P.I., Azeotropic Distillation in a Middle Vessel Batch Column. 2.Nonlinear Separation Boundaries. Industrial \& Engineering Chemistry Research, 38, 1531-1548 (1999b). 
Cheong, W. and Barton, P.I., Azeotropic Distillation in a Middle Vessel Batch Column. 3. Model Validation. Industrial \& Engineering Chemistry Research, 38, 1549-1564 (1999c).

Davidyan, A.G., Kiva, V.N., Meske, G.A., Morari, M., Batch distillation in a columnc with a middle vessel. Chemical Engineering Science, 49 30333051 (1994).

Diwekar, U., Batch Distillation _ Simulation, Optimal Design, and Control, Second Edition. Taylor \& Francis Group, Boca Raton (2011).

Fanaei, M., Dehghani, H., Nadi, S., Comparing and controlling of three batch distillation column configurations for separating tertiary zeotropic mixtures. Scientia Iranica, 19 (6) 1672-1681 (2012).

Fang, J., Li, C., Wang, H., Sun, L., A quasi-steadystate model for numerical simulation of batch extractive distillation. Chinese Journal of Chemical Engineering, 18 (1) 43-47 (2010).

García, A., Loría, J., Marín, A., Quiroz, A., Simple multicomponent batch distillation procedure with a variable reflux policy. Brazilian Journal of Chemical Engineering, 31 (2) 531-542 (2014).

Gruetzmann, S. and Fieg, G., Startup operation of middle-vessel batch distillation column: modeling and simulation. Industrial \& Engineering Chemistry Research, 47 (3) 813-824 (2008).

Gruetzmann, S., Fieg, G., Kapala, T., Theoretical analysis and operating behaviour of a middle vessel batch distillation with cyclic operation. Chemical Engineering and Processing: Process Intensification, 45 (1) 46-54 (2006).

Jain, S., Kim, J.-K., Smith, R., Operational Optimization of Batch Distillation Systems. Industrial \& Engineering Chemistry Research, 51 (16) 5749-5761 (2012).

Jimenez, L., Basualdo, M., Gómez, J., Toselli, L., Rosa, M., Nonlinear dynamic modeling of multicomponent batch distillation: a case study. Brazilian Journal of Chemical Engineering, 19 (3) 307-317 (2002).

Khazraee, S. and Jahanmiri, A., Composition estimation of reactive batch distillation by using adaptive neuro-fuzzy inference system. Chinese Journal of Chemical Engineering, 18 (4) 703-710 (2010).

Leipold, M., Gruetzmann, S., Fieg, G., An evolutionary approach for multi-objective dynamic optimization applied to middle vessel batch distillation.
Computers \& Chemical Engineering, 33 (4) 857 870 (2009).

Lopes, M.M. and Song, T.W., Batch distillation: Better at constant or variable reflux? Chemical Engineering and Processing: Process Intensification, 49 (12) 1298-1304 (2010).

Low, K. and Sørensen, E., Optimal operation of extractive distillation in different batch configurations. AIChE Journal, 48 (5) 1034-1050 (2002).

Luyben, W.L., Aspen Dynamics simulation of a middle-vessel batch distillation process. Journal of Process Control, 33 49-59 (2015).

Meski, G.A. and Morari, M., Design and Operation of a Batch Distillation Column with a Middle Vessel. Computers them Engng, 19, S597-S602 (1995).

Modla, G., Reactive pressure swing batch distillation by a new double column system. Computers \& Chemical Engineering, 35 (11) 2401-2410 (2011).

Modla, G., Separation of a chloroform-acetonetoluene mixture by pressure-swing batch distillation in different column configurations. Industrial \& Engineering Chemistry Research, 50 (13) 82048215 (2011).

Mujtaba, I.M., Batch distillation: design and operation. World Scientific Publishing Company, London (2004).

Narvaes-Garcia, A., Zavala-Loria, J., Vilchiz-Bravo, L., Rocha-Uribe, J., Performance indices to design a multicomponent batch distillation column using a shortcut method. Brazilian Journal of Chemical Engineering, 32 (2) 595-608 (2015).

Navarrete-Contreras, S., Sánchez-Ibarra, M., Barroso-Muñoz, F.O., Hernández, S., CastroMontoya, A.J., Use of glycerol as entrainer in the dehydration of bioethanol using extractive batch distillation: Simulation and experimental studies. Chemical Engineering and Processing: Process Intensification, 77 38-41 (2014).

Pacheco-Basulto , J.Á., Hernández-McConville, D., Barroso-Muñoz, F.O., Hernández, S., SegoviaHernández, J.G., Castro-Montoya, A.J., BonillaPetriciolet, A., Purification of bioethanol using extractive batch distillation: Simulation and experimental studies. Chemical Engineering and Processing: Process Intensification, 61 30-35 (2012).

Phimister, J.R. and Seider, W.D., Distillate-Bottoms Control of Middle-Vessel Distillation Columns. Industrial \& Engineering Chemistry Research, 39, 1840-1849 (2000a). 
Phimister, J.R. and Seider, W.D., Semicontinuous, Middle-Vessel Distillation of Ternary Mixtures. AIChE Journal, 46, 1508-1520 (2000b).

Quintero-Marmol, E. and Luyben, W.L., Multicomponent Batch Distillation. 2. Comparison of Alternative Slop Handling and Operating Strategies. Industrial \& Engineering Chemistry Research, 29 1515-1921 (1990).

Rao, C.S. and Barik, K., Modeling, Simulation and Control of Middle Vessel Batch Distillation Column. Procedia Engineering, 38 2383-2397 (2012).

Repke, J.-U., Klein, A., Bogle, D., Wozny, G., Pressure swing batch distillation for homogeneous azeotropic separation. Chemical Engineering Research and Design, 85 (4) 492-501 (2007).

Rivera, D.E., Morari, M., Skogestad, S., Internal model control: PID controller design. Industrial \& Engineering Chemistry Process Design \& Development, 25 (1) 2163-2163 (1986).

Skogestad, S., Simple analytic rules for model

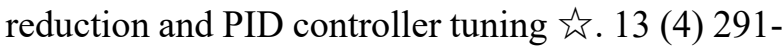
309 (2003).

Skogestad, S., Tuning for Smooth PID Control with Acceptable Disturbance Rejection. Industrial \& Engineering Chemistry Research, 45 (23) 78177822 (2006).

Tyreus, B.D. and Luyben, W.L., Tuning PI controllers for integrator/dead time processes. Industrial \& Engineering Chemistry Research, 31 (11) 26252628 (1992).

Wang, Y., Zhang, Z., Zhao, Y., Liang, S., Bu, G., Control of extractive distillation and partially heatintegrated pressure-swing distillation for separating azeotropic mixture of ethanol and tetrahydrofuran. Industrial \& Engineering Chemistry Research, 54 (34) 8533-8545 (2015).
Warter, M., Demicoli, D., Stichlmair, J., Batch distillation of zeotropic mixtures in a column with a middle vessel. European Symposium on Computer Aided Process Engineering, 10 385-390 (2002).

Warter, M., Demicoli, D., Stichlmair, J., Operation of a batch distillation column with a middle vessel: experimental results for the separation of zeotropic and azeotropic mixtures. Chemical Engineering and Processing: Process Intensification, 43 (3) 263272 (2004).

Warter, M. and Stichlmair, J., Batch Distillation of Azeotropic Mixtures in a Column with a Middle Vessel. European Symposium on Computer Aided Process Engineering, 10 691-696 (2000).

Wei, H.-M., Wang, F., Zhang, J.-L., Liao, B., Zhao, N., Xiao, F.-k., Wei, W., Sun, Y.-H., Design and control of dimethyl carbonate-methanol separation via pressure-swing distillation. Industrial \& Engineering Chemistry Research, 52 (33) 1146311478 (2013).

Xu, H., Ye, Q., Zhang, H., Qin, J., Li, N., Design and control of reactive distillation-recovery distillation flowsheet with a decanter for synthesis of N-propyl propionate. Chemical Engineering and Processing: Process Intensification, 85 38-47 (2014).

Zhu, Z., Li, X., Cao, y., Liu, X., Wang, Y., Design and Control of a Middle Vessel Batch Distillation Process for Separating the Methyl FormateMethanolWater Ternary System. Industrial \& Engineering Chemistry Research, 55 2760-2768 (2016).

Zhu, Z., Wang, L., Ma, Y., Wang, W., Wang, Y., Separating an azeotropic mixture of toluene and ethanol via heat integration pressure swing distillation. Computers \& Chemical Engineering, 76 137-149 (2015). 